\title{
Passively Q-switched Erbium-doped Fiber Laser Based on Iron Disulfide as a Saturable Absorber
}

\author{
N. Ahmed, N.F. Zulkipli, S. Omar, Z. Jusoh, H.A. Rahman, B. Musa and S.W. Harun
}

\begin{abstract}
This work highlights the demonstration of a passively Q-switched pulse laser with iron disulfide $\left(\mathrm{FeS}_{2}\right)$ as a saturable absorber in near-infrared region. The $\mathrm{FeS}_{2}$ saturable absorber is fabricated using liquid exfoliation method. A small piece of the $\mathrm{FeS}_{2}-\mathrm{SA}$ film is incorporated into the erbium-doped fiber laser ring cavity resulting in stable repetition rate from $80.4 \mathrm{kHz}$ to 88.5 kHz. The laser delivered a pulse duration that decreases from $12.43 \mu \mathrm{s}$ to $11.3 \mu \mathrm{s}$. By tuning the power pump from $125.2 \mathrm{~mW}$ to $166.4 \mathrm{~mW}$, maximum output power and pulse energy are recorded at $2.2 \mathrm{~mW}$ and $24.8 \mathrm{~nJ}$ respectively. Therefore, this work reveals that $\mathrm{FeS}_{2}$ has good nonlinear saturable absorption properties to produce a stable pulse at $1559.8 \mathrm{~nm}$ central wavelength.
\end{abstract}

Index Terms-erbium-doped fiber laser, iron sulfide, Q-switching, saturable absorber.

\section{INTRODUCTION}

$\mathrm{T}$ HE short pulse fiber lasers generated from a passive Qswitcher still offers a tremendous applications such as material cutting [1], oral and maxillofacial surgery [2] and optical communications [3]. To date, many researchers prefer passive techniques rather than active since it is more flexible, cost effective and compact. This technique requires a nonlinear absorptions material known as saturable absorber, that is capable to modulate the Q-factor of fiber ring laser and then generates pulse train as short as femtoseconds [4]. In early 1990s, semiconductor saturable absorber mirrors (SESAMs) had led the work as a Q-switcher followed by graphene that was discovered in 2004. Both materials have been making outstanding debut for years. However, the limitations on the operating bandwidth and high cost with a complex fabrication of SESAMs [5] and a small modulation depth per layer of graphene [6], hinder the potential of these saturable absorber (SA).

This manuscript is submitted on 18 March 2021 and accepted on 4 June 2021.N. Ahmed, S.omar, Z. Jusoh and B. Musa are from School of Electrical Engineering, Universiti Teknologi MARA Cawangan Terengganu, Kampus Dungun, $23000 \quad$ Dungun, Terengganu, Malaysia (email:noriz207@uitm.edu.my).

H. A. Rahman is from School of Electrical Engineering, Universiti Teknologi MARA (UiTM), 40450 Shah Alam, Selangor, Malaysia (e-mail: husna232@uitm.edu.my).

N. F. Zulkipli and S. W. Harun are from Photonics Engineering Laboratory, Department of Electrical Engineering, University of Malaya, Kuala Lumpur 50603, Malaysia. (e-mail: swharun@um.edu.my).

1985-5389/C 2021 The Authors. Published by UiTM Press. This is an open access article under the CC BY-NC-ND license (http://creativecommons.org /licenses/by-nc-nd/4.0/).
Thus far, various types of materials have been actively explored such as single-wall carbon nanotubes (SWCNTs) [7][8][9] and quantum dots (QDs) [10][11][12]. In addition, recent research trend shows a growing interest in two-dimensional (2D) materials such as transition metal dichalcogenides (TMDs) (e.g., $\mathrm{MoS}_{2}, \mathrm{MoSe}_{2}, \mathrm{WS}_{2}$ ), transition metal oxides (TMOs) (e.g., $\mathrm{TiO}_{2}, \mathrm{ZnO}, \mathrm{NiO}$ ), topological insulators $\left(\mathrm{BiSb}, \mathrm{Bi}_{2} \mathrm{Te}_{3}\right.$, $\mathrm{Bi}_{2} \mathrm{Se}_{3}$ ) and black phosphorus (BP).

The demonstrations of Q-switched lasers of $\mathrm{MoS}_{2}$ [13], $\mathrm{Ws}_{2}$ [14], $\mathrm{TiO}_{2}$ [15], $\mathrm{Er}_{2} \mathrm{O}_{3}$ [16], $\mathrm{Bi}_{2} \mathrm{Se}_{3}$ [17] and $\mathrm{BP}$ [18] had verified complementary properties of these $2 \mathrm{D}$ materials that can initiate Q-switching pulsation. These remarkable properties of 2D materials have stimulated a significant research interest in searching for a novel Q-switcher that can lead to high performance lasers. Moreover, 2D materials shared many similar properties such as Pauli blocking induced saturable absorption as well as ultrafast relaxation time, and high optical nonlinearity [19]. Pyrite $\left(\mathrm{FeS}_{2}\right)$ or formally known as iron disulfide, has great potential to be directed towards photonic applications. It has a bandgap of $\approx 0.95 \mathrm{eV}$ with a high optical absorption capacity [20]. The crystal structure with unique electrical and optical properties of $\mathrm{FeS}_{2}$ have been widely used for the applications in solar cell material [21] and photodetectors [22]. The above investigations have clearly shown the feasibility of this material, hence, the potential of $\mathrm{FeS}_{2}$ in the applications of photonic devices must be explored.

This article demonstrates a passively Q-switched erbiumdoped fiber laser using $\mathrm{FeS}_{2}$-based $\mathrm{SA}$. $\mathrm{FeS}_{2}$-SA thin film was fabricated using liquid-phase exfoliation method which offers simplicity and low cost. The thin film was successfully incorporated into the erbium-doped fiber laser ring cavity and was able to operate a Q-switched with an average output power of $2.2 \mathrm{~mW}$. The repetition rate was tuned from $80.4 \mathrm{kHz}$ to $88.5 \mathrm{k} \mathrm{Hz}$ and a decreasing pulse width that varies from 12.43 $\mu$ s to $11.3 \mu$ s was obtained. The central wavelength of 1559.8 $\mathrm{nm}$ was observed under a maximum input pump power of 166.4 $\mathrm{mW}$. This indicates that $\mathrm{FeS}_{2}$-SA is indeed a promising Qswitcher in pulsed laser applications. 


\section{IRON DisUlfide FILM PREPARATION AND OPTICAL CHARACTERIZATION}

The concentration with thickness of the SA film is the essential parameter for pulse generation in passive optical fibers. The preparation of $\mathrm{FeS}_{2}$ film was started by dissolving 1 gram of polyvinyl alcohol (PVA) powder into $120 \mathrm{ml}$ of distilled water. A magnetic stirrer was used to stir the mixture for about 24 hours at $100^{\circ} \mathrm{C}$ temperature. $50 \mathrm{ml}$ of the prepared PVA solution is mixed with $15 \mathrm{mg}$ of $\mathrm{FeS}_{2}$ powder as illustrated

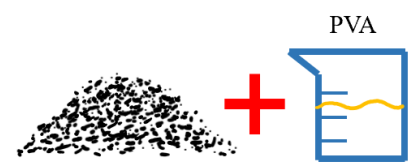

$\mathrm{FeS}_{2}$ powder
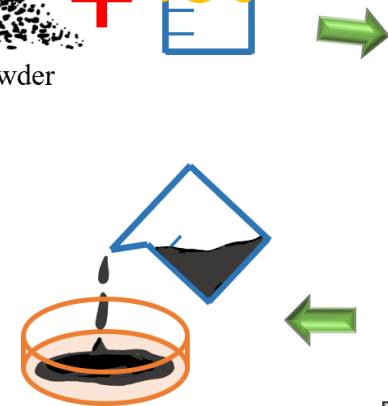

Drop $\mathrm{FeS}_{2}$-PVA solution into petri dish and left to dry at room temperature

Fig. 1. $\mathrm{FeS}_{2}-\mathrm{SA}$ preparation.

in Fig. 1. The mixture was further stirred at $300 \mathrm{rpm}$ speed for 12 hours. In liquid-phase exfoliation (LPE) method, a high intensity of ultra-sonication by applying a sound energy higher than $20 \mathrm{kHz}$ is required to create microbubbles and forces in order to break the van der Waals force between molecules, or in other words, remove particles that are not absorbed. The ultra-sonication bath was applied for 1 hour. Finally, $\mathrm{FeS}_{2}$-PVA solution was left to dry at room temperature in a petri dish and used for characterizations.

A sample of $\mathrm{FeS}_{2}-\mathrm{SA}$ is characterized using field emission scanning electron microscopy (FESEM), as shown in Fig. 2.

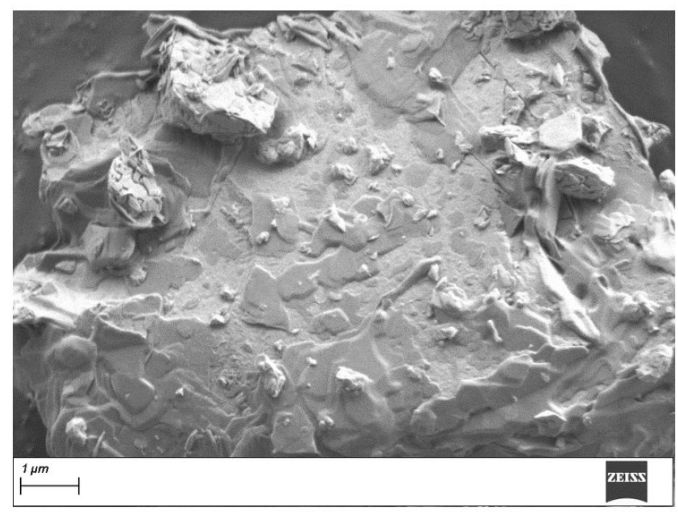

Fig. 2. FESEM image.
The energy dispersive X-ray spectroscopy (EDS) profile in Fig. 3 testifies the presence of Iron and Sulfur elements in the film. Fig. 4 depicts the linear absorption measurement of $\mathrm{FeS}_{2}$ SA. The absorption of $5.6 \mathrm{~dB}$ occurs at $1559.8 \mathrm{~nm}$. A technique known as a twin-balanced detector measurement were performed in order to measure the nonlinear optical absorption. From the profile shown in Fig. 5, $\mathrm{FeS}_{2}$-based $\mathrm{SA}$ has a modulation depth, a saturable intensity, and a nonsaturable absorption of $4.8 \%, 0.11 \mathrm{MW} / \mathrm{cm} 2$ and $12.7 \%$, respectively.

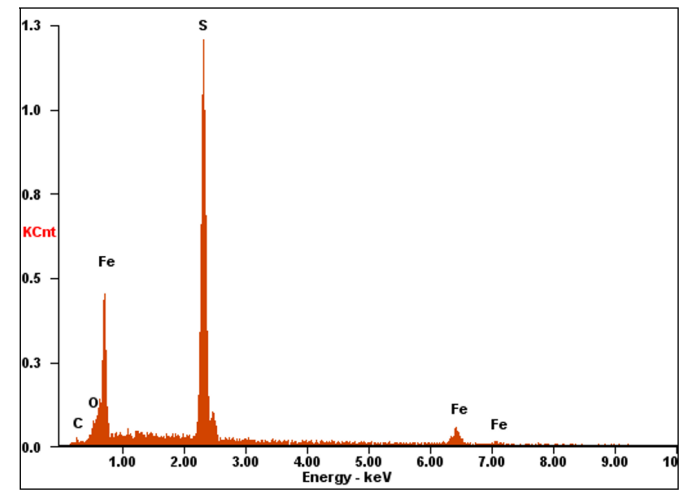

Fig. 3. EDS profile of $\mathrm{FeS}_{2}-\mathrm{SA}$

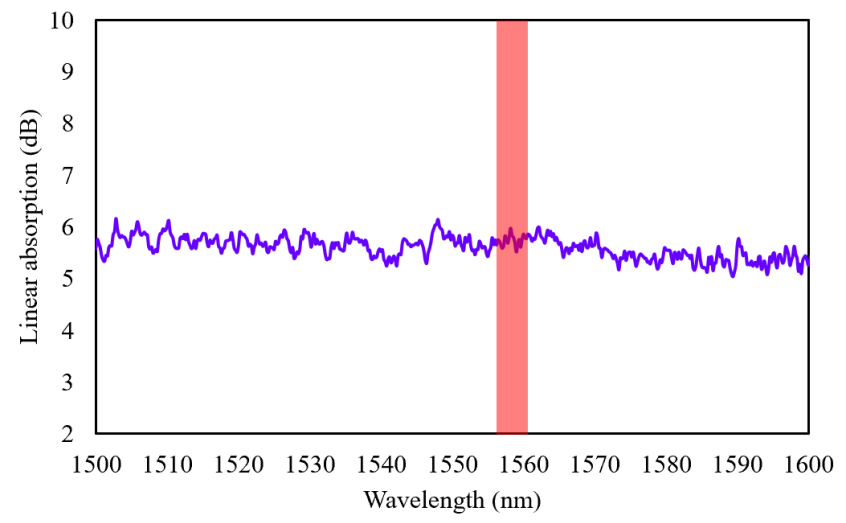

Fig. 4. Linear absorption measurement.

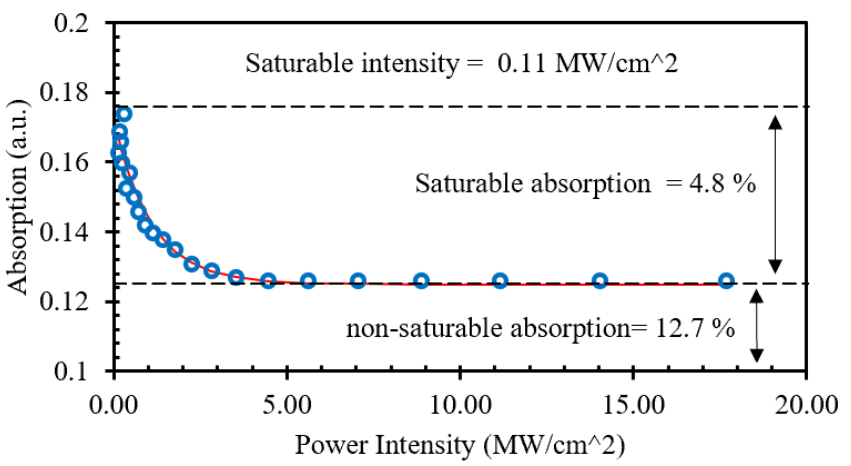

Fig. 5. Nonlinear optical profile of $\mathrm{FeS}_{2}$-SA.

\section{ERBIUM-DOPED FIBER LASER (EDFL) SETUP}

Fig.6. described the configuration of all-fiber ring cavity setup of the EDFL with $\mathrm{FeS}_{2}$ based SA. The input for the EDF 
was pumped from a $980 \mathrm{~nm}$ laser diode via a 980/1550 nm wavelength-division multiplexing (WDM). A $2.4 \mathrm{~m}$ long erbium-doped fiber (EDF) with a coefficient of absorption of $23.9 \mathrm{~dB} / \mathrm{m}$ at $979 \mathrm{~nm}$, a numerical aperture (NA) of 0.24 , a fibre diameter of $125.4 \mu \mathrm{m}$ and a core diameter of $5.8 \mu \mathrm{m}$ was used as the gain medium. An isolator (ISO) was positioned after the EDF to ensure unidirectional signal propagation. $\mathrm{FeS}_{2}-\mathrm{SA}$ was deposited into the optical fiber ferrule, as shown in Fig. 7.

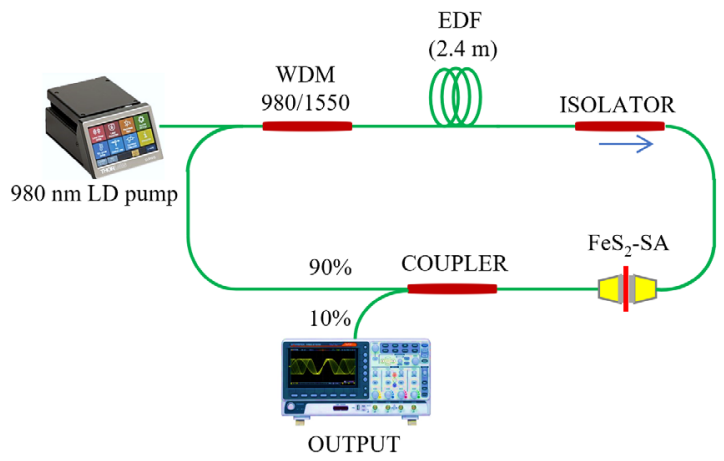

Fig. 6. Ring cavity setup of the EDFL Q-switched.

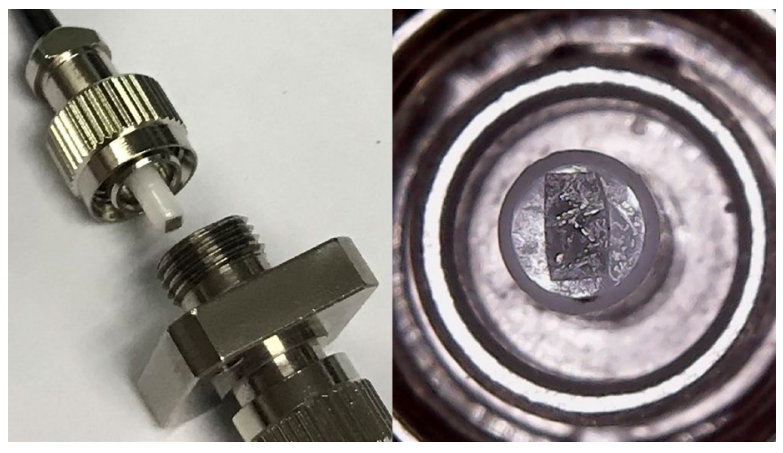

Fig. 7. $\mathrm{FeS}_{2}$ film on fiber ferrule.

The SA continually modulates the Q-factor of the cavity and generates Q-switched laser pulses. A $3 \mathrm{~dB}$ coupler was applied at the end of the ring cavity to extract $10 \%$ of the lasing output while the rest was recirculated within the cavity via the 1550 $\mathrm{nm}$ port of the WDM. The passive Q-switching output spectrum resulted from the $\mathrm{FeS}_{2}-\mathrm{SA}$ was measured using an optical spectrum analyzer with a $0.03 \mathrm{~nm}$ resolution. A $500-\mathrm{MHz}$ digital oscilloscope and a radio frequency spectrum analyzer (RFSA) were used to observe the stability and quality of the Qswitched pulse traces. The output power of the developed EDFL was measured using an optical power meter (OPM).

\section{Q-SWITCHED EDFL PERFORMANCES}

When $\mathrm{FeS}_{2}$-SA film was incorporated into the ring cavity, a stable Q-switching was observed at pump power, starting at $125.2 \mathrm{~mW}$. The Q-switched lasing appeared stable when the pump power was continuously increased to $166.4 \mathrm{~mW}$. It was observed that when the pump power was increased to higher pump power for more than 20 minutes, the pulse laser was still stable with no damage. This incident indicates that the laser operates below the damage threshold thus verifies that $\mathrm{FeS}_{2}$ is a good SA. As illustrated in Fig.8, the EDFL Q-switched laser operates at a central wavelength of $1559.8 \mathrm{~nm}$. The signal to noise ratio (SNR) at maximum pump power of $166.4 \mathrm{~mW}$ in Fig.9, indicates a stable RF spectrum regime of Q-switched laser at $55 \mathrm{~dB}$. Fig. 10 depicts the Q-switched pulse train at $166.4 \mathrm{~mW}$ pump power and $88.5 \mathrm{kHz}$ of repetition rate.

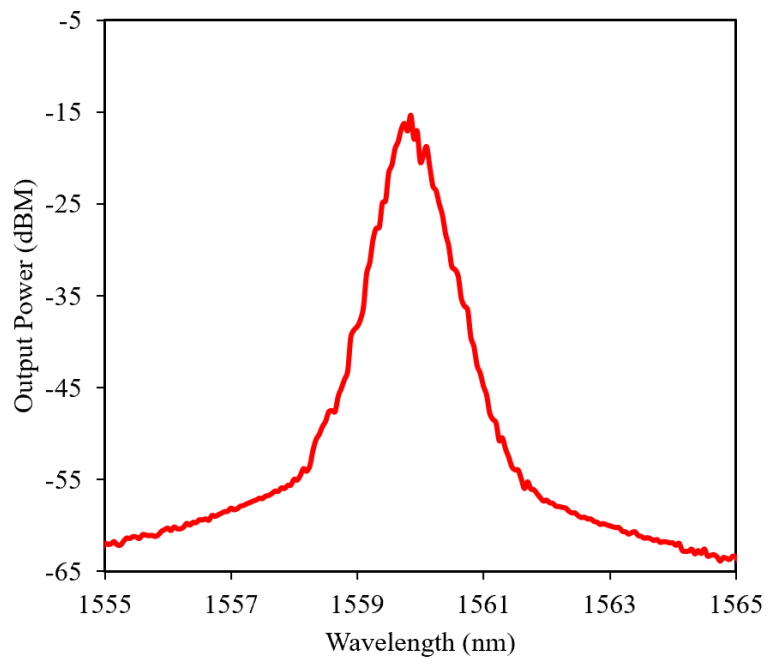

Fig. 8. The output spectrum.

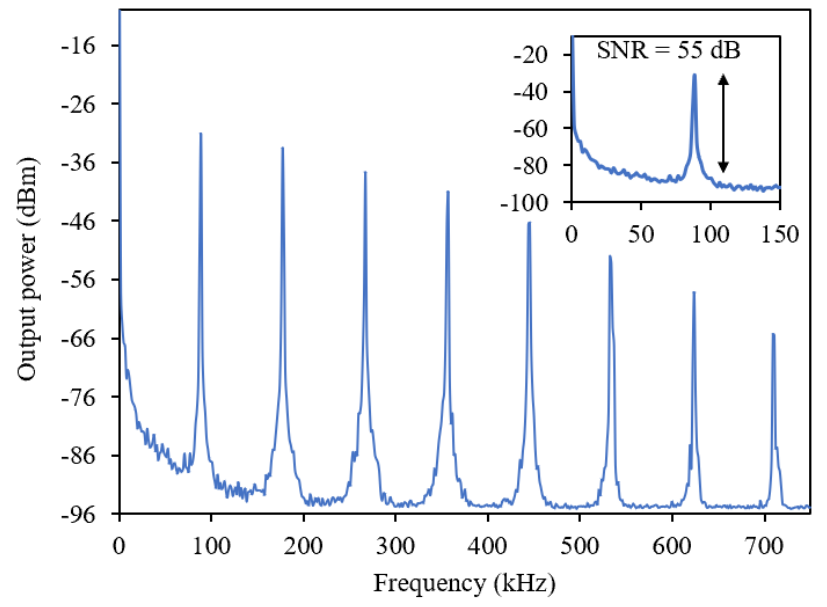

Fig. 9. RF spectrum at $166.43 \mathrm{~mW}$ of pump power.

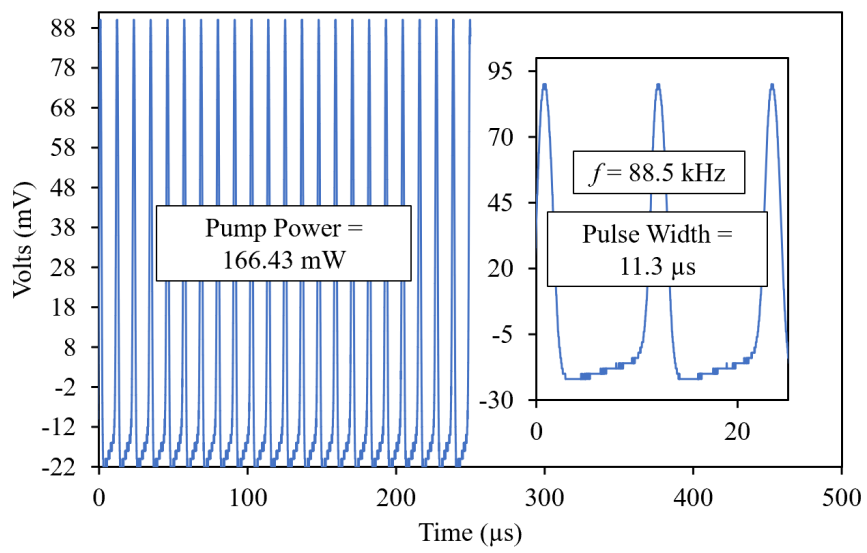

Fig. 10. Stability of pulse train at a pump power of $166.43 \mathrm{~mW}$ 
As shown in Fig. 11, increasing the pump power in the range of $125.2 \mathrm{~mW}$ to $166.4 \mathrm{~mW}$, increases the repetition rate from $80.4 \mathrm{kHz}$ to $88.5 \mathrm{kHz}$ and decreases the pulse duration from $12.4 \mu \mathrm{s}$ to $11.3 \mu \mathrm{s}$. The figure shows a typical pattern of a passive Q-switched performance. The measured pump power against pulse energy and output power is depicted in Fig. 12. The output power increases steadily with a slope efficiency of $1.5 \%$, showing the same increasing pattern with the pulse energy. The highest output power and pulse energy were recorded at $2.2 \mathrm{~mW}$ and $24.8 \mathrm{~nJ}$ respectively. This work's proposed laser is capable of delivering a Q-switched output that has high stability, high pulse repetition rate and high pulse energy, thus confirming that the developed passive EDFL with $\mathrm{FeS}_{2}$-SA has a significant potential in photonics applications.

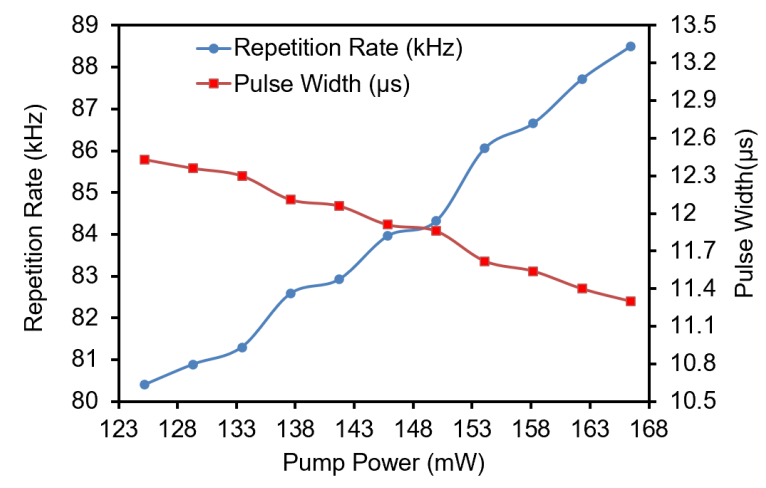

Fig. 11. Repetition rate and pulse width of the input laser.

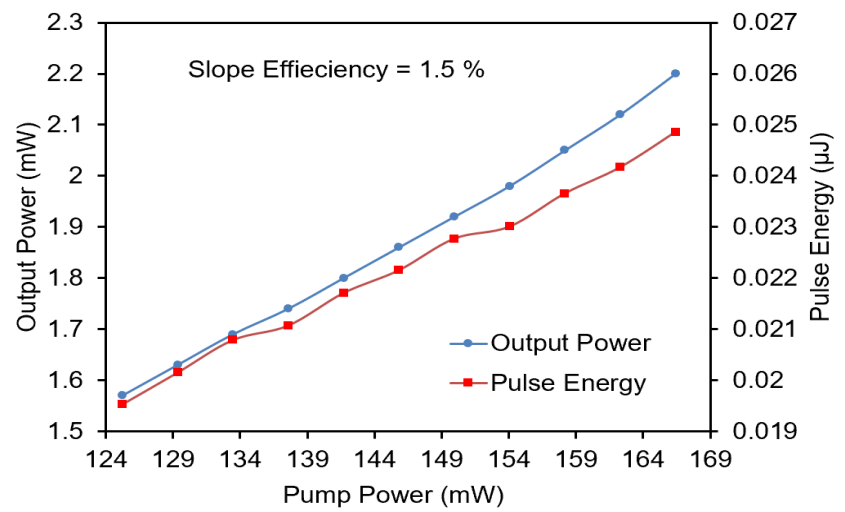

Fig. 12. Average power and peak pulse power of the input laser versus pump power.

Table I shows the comparison of output performance by different SAs in Q-switched EDFL. Optimization of EDFL ring cavity and nonlinear saturable absorption properties such as saturable intensity and modulation depth, should provide further improvements in performance.
TABLE I

COMPARISON OF OUTPUT PERFORMANCE BY DIFFERENT SAs IN Q-SWITCHED EDFL

\begin{tabular}{ccccc}
\hline $\begin{array}{c}\text { Saturable } \\
\text { absorber }\end{array}$ & $\begin{array}{c}\text { SNR } \\
(\mathbf{d B})\end{array}$ & $\begin{array}{c}\text { Max. pulse repetition } \\
\text { rate }(\mathbf{k H z})\end{array}$ & $\begin{array}{c}\text { Max. pulse } \\
\text { energy (nJ) }\end{array}$ & Ref. \\
\hline $\mathrm{Wse}_{2}$ & 46.7 & 49.6 & 33.2 & {$[23]$} \\
$\mathrm{PbS}$ & 63 & 38.7 & 10.6 & {$[24]$} \\
$\mathrm{CdSe}$ & 47 & 64 & 1.16 & {$[25]$} \\
$\mathrm{WSSe}$ & 57.8 & 61.8 & 7.31 & {$[26]$} \\
$\mathrm{FeS}_{2}$ & 55 & 88.5 & 24.8 & $\begin{array}{c}\text { This } \\
\text { work }\end{array}$ \\
\hline
\end{tabular}

\section{CONCLUSION}

This work proves that $\mathrm{FeS}_{2}$ based saturable absorber prepared by LPE method has succeeded in generating a Q-switched laser pulse at a central wavelength of $1559.8 \mathrm{~nm}$. A small piece of $\mathrm{FeS}_{2}$-SA thin film, in conjunction with EDFL, produced a laser pulse that started at pump power from 125.2 $\mathrm{mw}$ to $166.4 \mathrm{mw}$. The repetition rate is recorded from $80.4 \mathrm{kHz}$ to $88.5 \mathrm{kHz}$. As pulse width decreases from $12.43 \mu \mathrm{s}$ to $11.3 \mu \mathrm{s}$, the maximum pulse energy of $24.86 \mathrm{~nJ}$ and maximum output power of $2.2 \mathrm{mw}$ are obtained. The non-saturable absorbance, modulation depth and saturation intensity of $\mathrm{FeS}_{2}$ are $12.7 \%$, $4.8 \%$ and $0.11 \mathrm{MW} / \mathrm{cm}^{2}$ respectively. These results reveal that $\mathrm{FeS}_{2}$-SA has promising potential in pulsed laser applications.

\section{ACKNOWLEDGMENT}

The authors would like to thank the Photonic Engineering Lab, Department of Electrical, Faculty of Engineering, University of Malaya for their contribution to this work.

\section{REFERENCES}

[1] P. Gautam and K. K. Singh, "Experimental investigation and modeling of heat affected zone and surface roughness in erbiumdoped fiber laser cutting of CFRP composite," Mater. Today Proc., vol. 5, no. 11, pp. 24466-24475, 2018.

[2] T. J. Sawisch, Oral Surgery for the General Practitioner, First Edit. Copyright (C) 2011 by Mosby, Inc., an affiliate of Elsevier Inc., 2010.

[3] T. Krishnaswamy Subramaniam, "Erbium Doped Fiber Lasers for Long Distance Communication Using Network of Fiber Optics," Am. J. Opt. Photonics, vol. 3, no. 3, p. 34, 2015.

[4] C. Xu et al., "MXene (Ti 3 C 2 T," vol. 361, no. 8, pp. 255-266, 2020.

[5] W. Abdulkhaleq, S. Abdulhameed, I. A. M. Alani, and M. H. M. Ahmed, "Magnesium oxide ( $\mathrm{MgO}$ ) thin fi $\mathrm{lm}$ as saturable absorber for passively mode locked erbium-doped fi ber laser," Opt. Laser Technol., vol. 115, no. January, pp. 331-336, 2019.

[6] A. K. Geim and K. S. Novoselov, "The rise of graphene," Nanosci. Technol. A Collect. Rev. from Nat. Journals, pp. 11-19, 2009.

[7] Y. G. Wang, S. Y. Cheng, P. T. Tai, and J. Tang, "Saturable absorber at $940 \mathrm{~nm}$ using single wall carbon nanotubes deposited by vertical evaporation technique," Optik (Stuttg)., vol. 123, no. 4, pp. $348-351,2012$.

[8] S. Absorber, "Tunable Passively Q -switched Erbium-Doped," Technology, vol. 22, no. 1, pp. 2009-2011, 2010.

[9] Y. W. Song, S. Yamashita, and S. Maruyama, "Single-walled carbon nanotubes for high-energy optical pulse formation," Appl. Phys. Lett., vol. 92, no. 2, pp. 1-4, 2008.

[10] Y. Fu et al., "Low- and high-order nonlinear optical properties of Ag 2 S quantum dot thin films," Nanophotonics, vol. 8, no. 5, pp. 849-858, 2019.

[11] L. Yun et al., "PbS quantum dots as a saturable absorber for ultrafast laser," Photonics Res., vol. 6, no. 11, p. 1028, 2018.

[12] J. Du et al., "Phosphorene quantum dot saturable absorbers for 
ultrafast fiber lasers," Sci. Rep., vol. 7, no. January, pp. 1-10, 2017. N. N. Razak, M. Yasin, Z. Zakaria, A. A. Latiff, and S. W. Harun, "Q-switched fiber laser with a tungsten disulfide saturable absorber prepared by the drop casting method," Photonics Lett. Pol., vol. 9, no. 3, pp. 103-105, 2017.

[14] H. Ahmad et al., "Passively Q-switched erbium-doped fiber laser at C-band region based on WS_2 saturable absorber," Appl. Opt., vol. 55, no. 5, p. $1001,2016$.

[15] H. Ahmad, Z. A. Ali, and M. A. Ismail, "C-Band Q-Switched Fiber Laser Using Titanium Dioxide ( $\mathrm{TiO} 2$ ) As Saturable Absorber CBand Q-Switched Fiber Laser Using," vol. 8, no. 1, 2016.

[16] M. F. Baharom, N. F. Zulkefli, M. B. H. Mahyuddin, A. A. Latiff, A. R. Muhammad, and S. W. Harun, "Erbium Oxide as new Saturable Absorber for Short-Pulse Generation at 1.55-micron region," J. Phys. Conf. Ser., vol. 1151, no. 1, 2019.

[17] Z. Yu et al., "High-repetition-rate Q-switched fiber laser with high quality topological insulator Bi_2Se_3 film," Opt. Express, vol. 22, no. 10, p. 11508, 2014.

[18] Z. Qin et al., "Black phosphorus as saturable absorber for the Qswitched Er:ZBLAN fiber laser at $28 \mu \mathrm{m}$," Opt. Express, vol. 23, no. 19 , p. $24713,2015$.

[19] K. Wu et al., "High-performance mode-locked and Q-switched fiber lasers based on novel 2D materials of topological insulators, transition metal dichalcogenides and black phosphorus: review and perspective (invited)," Opt. Commun., vol. 406, no. February, pp. 214-229, 2018.

[20] D. Banjara, Y. Malozovsky, L. S. Franklin, and D. Bagayoko, "First-principles studies of electronic, transport and bulk properties of pyrite FeS2," AIP Adv., vol. 8, no. 2, 2018.

[21] G. S. Chandrawat, J. Tripathi, A. Sharma, J. Singh, S. Tripathi, and J. Chouhan, "Study of structural and optical properties of FeS2 nanoparticles prepared by polyol method," J. Nano-Electron. Phys., vol. 12 , no. 2, pp. 2-5, 2020.

[22] S. Liu et al., "Phase-pure iron pyrite nanocrystals for low-cost photodetectors," Nanoscale Res. Lett., vol. 9, no. 1, pp. 1-7, 2014. B. Chen, X. Zhang, C. Guo, K. Wu, J. Chen, and J. Wang,

"Tungsten diselenide Q-switched erbium-doped fiber laser," Opt. Eng., vol. 55, no. 8, p. 081306, 2016.

[24] X. Sun, B. Zhou, W. Zhao, T. Wang, and C. Mou, "Passively Qswitched Erbium-doped fiber lasers using PbS polystyrene film as saturable absorber," ICOCN 2017 - 16th Int. Conf. Opt. Commun. Networks, vol. 2017-Janua, pp. 1-2, 2017.

[25] A. H. A. Rosol et al., "Cadmium Selenide Polymer Microfiber Saturable Absorber for Q-Switched Fiber Laser Applications," Chinese Phys. Lett., vol. 34, no. 9, 2017.

[26] H. Ahmad, Z. C. Tiu, and S. I. Ooi, "Passive Q -switching in an erbium-doped fiber laser using tungsten sulphoselenide as a saturable absorber," Chinese Opt. Lett., vol. 16, no. 2, pp. 1-5, 2018.

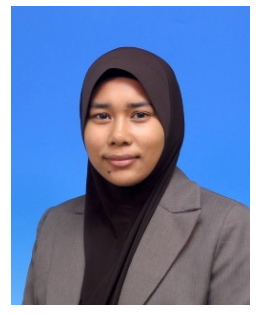

N.Ahmed received her Bachelor in engineering (electrical) and Master of science in telecommunication and information engineering from Universiti Teknologi MARA (UiTM), Malaysia. She is a senior lecturer at the Faculty of Electrical Engineering, Universiti Teknologi MARA, Terengganu branch. She is currently pursuing her $\mathrm{PhD}$ at Universiti Teknologi MARA (UiTM), Malaysia, working on the passive erbium-doped fiber laser (EDFL).

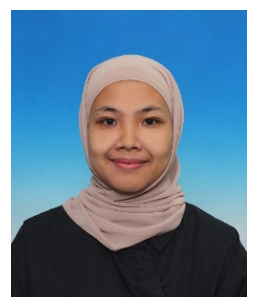

N.F. Zulkipli received M.Eng degree from University of Malaya in 2017. Currently she is pursuing her $\mathrm{PhD}$ in the Department of Electrical Engineering, University of Malaya.

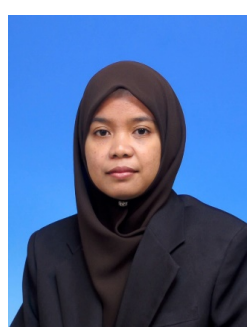

S. Omar received her Bachelor degree in electrical engineering with honours from Universiti Teknologi MARA (UiTM), Malaysia. She received her Master degree in telecommunication and information engineering also from UiTM. She is a senior lecturer at the Faculty of Electrical Engineering, Universiti Teknologi MARA, Terengganu branch. She is currently pursuing her PHD at Universiti Teknologi MARA (UiTM), Malaysia, focusing on the nanophotonic and fiber optics.

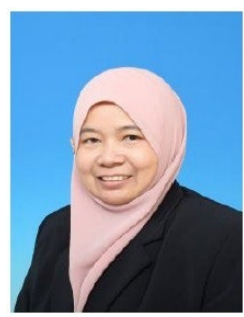

Z. Jusoh received her BEng and Meng from University of Malaya in 2002 and 2008, respectively. She received her PhD in Optical Communication Engineering from University of Malaya in 2015. Currently she is a senior lecturer at the Faculty of Electrical Engineering, Universiti Teknologi MARA, Terengganu branch and her research interest in Photonics and Optical Sensors.

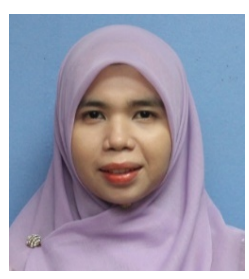

H.A. Rahman received her B. Eng (Hons) from Multimedia University, Malaysia in 2002. Her MSc degree is in mobile communication system from University of Surrey, UK and her Ph.D degree is in Photonics from University of Malaya in 2005 and 2014, respectively. She is also a senior lecturer at the Faculty of Electrical Engineering, Universiti Teknologi MARA (UiTM), Malaysia. Her research interests include fiber optic sensors and waveguides.

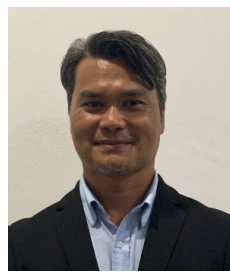

B. Musa received his BSc (Hon) in Physics from the University of Malaya, MSc in Advanced Materials from Universiti Teknologi MARA and PhD in Photonics and Fiber Optic System Engineering from Univeriti Putra Malaysia. He is currently a senior lecturer at the Faculty of Electrical Engineering, Universiti Teknologi MARA, Terengganu branch. His research interests are tapered fiber-based optical sensors, optical materials and generation of pulsed lasers using passive saturable absorbers.

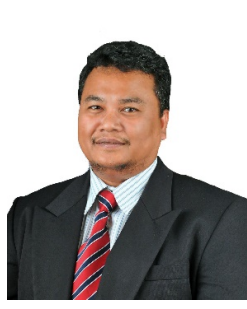

S.W. Harun received the BEng degree in Electrical and Electronics System Engineering from Nagaoka University of Technology, Japan in 1996, and MSc and $\mathrm{PhD}$ degrees in Photonics from University of Malaya in 2001 and 2004, respectively. Currently, he is a full professor at the Faculty of Engineering, University of Malaya. His research interests include fiber optic active and passive devices. 